\title{
The tale of lenalidomide clinical superiority over thalidomide and regulatory and cost-effectiveness issues
}

\author{
A narrativa de que a lenalidomida é clinicamente superior à \\ talidomida, e questões regulatórias e de custo-efetividade
}

Francisco José Roma Paumgartten (http://orcid.org/0000-0002-6207-0149) ${ }^{1}$

${ }^{1}$ Escola Nacional de Saúde Pública, Fiocruz. Av. Brasil 4036/913, Manguinhos. 21040-361 Rio de Janeiro RJ Brasil.paum@ensp. fiocruz.br

\begin{abstract}
In April 2017, the National Sanitary Surveillance Agency (ANVISA-Brazil) approved lenalidomide (LEN) for multiple myeloma (MM) and myelodysplastic syndrome. ANVISA had rejected the first application in 2010, and denied a request for reconsideration in 2012. The reason for rejection was the lack of comparative effectiveness studies proving that LEN was more effective than thalidomide (THAL), a strictly controlled drug regulated by Federal law 10.651/2003 and dispensed to patients (at no costs) through public health system units and hospitals. ANVISA unexplained retreat on the LEN approval for marketing was an unquestionable triumph of the lobbying that ensued the denial, at the forefront of which were politicians, Congress members, patient organizations and medical societies. Two randomized (phase III) trials and three observational (casecontrol and population-based cohort) compared the effectiveness of THAL- versus LEN-based therapies in MM. Overall, these studies showed no difference in efficacy between LEN- and THAL -based therapies. LEN caused less neuropathy, and more severe hematologic adverse effects. It is much costlier than THAL, and substitution of THAL by LEN shall raise considerably public healthcare costs in Brazil.

Keywords Multiple myeloma, Cost-effectiveness, Cancer, Healthcare costs.
\end{abstract}

Resumo A Agência Nacional de Vigilância Sanitária (ANVISA) aprovou em abril de 2017 a lenalidomida (LEN) para o mieloma múltiplo (MM) e síndrome mielodisplásica. A ANVISA havia negado o registro em 2010, e indeferido um recurso apresentado em 2012. O motivo do indeferimento foi a falta de estudos comparativos de efetividade demonstrando que LEN era mais eficaz do que a talidomida (TAL), um medicamento rigorosamente controlado pela lei federal 10.651/2003 e dispensado gratuitamente a pacientes através de unidades de saúde e hospitais públicos. O recuo não explicado da ANVISA em relação ao registro da LEN foi um inquestionável triunfo do lobby que sucedeu a recusa inicial do registro, a frente do qual estavam políticos, membros do Congresso, associações de pacientes e sociedades médicas. Dois ensaios randomizados (fase III) e três estudos observacionais (caso-controle e coorte de base populacional) compararam a efetividade de terapias para o MM com TAL- e com LEN. Em conjunto, esses estudos mostraram que não havia diferenças quanto a eficácia de tratamentos com LEN- e aqueles com TAL. A LEN causou menos neuropatias, e efeitos adversos hematológicos mais graves. Ela é muito mais cara do que a TAL, e a substituição da TAL pela LEN aumentará muito os custos da assistência pública à saúde no Brasil.

Palavras-chave Mieloma múltiplo, Custo-efetividade, Câncer, Custos da assistência médica. 


\section{Introduction}

To grant marketing approval for a new medicine, a regulatory agency demands that the applicant presents evidence of its efficacy and safety for intended clinical uses. Along this line, the best empiric evidence that a drug is effective and safe, or that potential therapeutic benefits outweigh risks of harm to patients, is generally provided by good quality phase III randomized clinical trials (RCTs) controlled with a placebo, or with a therapy of proven effectiveness (active comparator), whenever the use of an inactive comparator is considered unethical.

The US FDA, EMA and most national regulatory agencies, however, do not require data on comparative effectiveness and safety, or evidence that a new drug is clinically superior to existing therapies. It follows that a newly approved drug is not necessarily better than preceding ones, and thus it may not add to existing therapies. This applies, for instance, to drugs called in pharmaceutical jargon terms "me-too" or "follow-on" drugs, or medicines sharing with a drug already on the market a similar chemical structure, an identical mechanism of action and the same therapeutic indications 1 . In other words, "me-too" drugs are not truly innovative or breakthrough medicines developed to treat a morbid condition; rather they are just "more of the same", or similar drugs that are not clinically superior to a pioneering one. "Me-too" medicines may be the outcome of a frustrated attempt to increase efficacy and or to attenuate the toxicity of a prototype drug by altering its molecule, or otherwise be a deliberate imitation of a pioneer medicinal product. Some authors believe that "me-too"s are wasteful duplications and propose that agencies' requirements for approving a new drug should be not only the evidence that it is effective and safe, but also a demonstration that it is clinically superior to pre-existing therapies. Others, however, are against imposing regulatory obstacles to the development of non-innovative and "me-too" drugs arguing that they enhance competition within the pharmaceutical market and, by doing so, they stimulate lowering prices what ultimately expands the access of low-income people to medicines ${ }^{1,2}$.

The National Sanitary Surveillance Agency (ANVISA-Brazil) policy for "me-too" drugs was made explicit in a comment posted on its website: ... it is difficult or even impossible to classify a (new) medicine as a "me-too" drug on the occasion it is (first) registered because some of its attributes that would allow us to make this classification can only be (fully) assessed after the product is marketed and used in large scale", and "...current Brazilian laws do not support denying registration of new drugs based on such argument. For the foregoing reasons, according to ANVISA's note, the agency does not necessarily reject applications of "metoo" drugs even if they, apparently, do not add to existing therapies ${ }^{2}$.

A major problem with non-innovative drugs is that pharmaceutical companies generally do not fairly and adequately inform doctors and consumers about the degree of similarity between new products and pre-existing ones. To boost sales of a new drug, companies almost invariably claim that their products are in some way better than preceding ones, even when this allegation is unsupported by comparative effectiveness (and safety) research data. A common allegation, for instance, is that it might be beneficial for a subgroup of patients who do not respond satisfactorily to similar drugs already on the market. In many cases, however, this claim is at best an untested - and self-regarding-hypothesis ${ }^{2}$. The hypothetical subpopulation of patients (who would respond differently to a new drug) is seldom, if ever, characterized by controlled clinical studies.

Lenalidomide, a teratogenic thalidomide-like drug (Figure 1), challenged Anvisa's viewpoint on "me-too" products, and rekindled the debate on whether the agency should require the applicant a proof of clinical superiority over existing therapies for granting a marketing approval for some drugs. A demand for comparative effectiveness research data are of utmost importance, for instance, if estimated costs of treatment with the new drug are much higher than the costs of therapies with drugs already available on the market.

This article appraises critically the available evidence on the comparative effectiveness of lenalidomide- versus thalidomide-based therapies for MM, and regulatory and cost-effectiveness issues behind lenalidomide authorization for sales in Brazil.

\section{Methods}

The approval of lenalidomide for sales in Brazil is discussed here as an exploratory case study. It brings us to question ANVISA's regulatory policy for non-innovative (me-too) drugs, particularly when the new product compares unfavorably with its prototype medicine in terms 
Figure 1. Lenalidomide resulted from two minor alterations in the phthalimide ring of thalidomide (indicated by circles). It is more potent than thalidomide (therapeutic doses: $15-25 \mathrm{mg} /$ day versus $100-200 \mathrm{mg} /$ day, respectively). Comparative effectiveness research, however, showed that they have nearly the same effectiveness in the treatment of multiple myeloma. Nonetheless, lenalidomide, compared with its prototype drug, was associated with a lower incidence of neuropathy and a higher occurrence of severe hematologic side effects.

of cost-effectiveness. Nonetheless, this case also involves another unique regulatory issue. Owing to its teratogenicity and the fact that the country has world's greatest number of thalidomide victims born after 1965 (i.e., "avoidable cases" of thalidomide birth defects), it is the only drug regulated by a specific Federal law in Brazil. The law 10.651/2003 forbids thalidomide sales, and further agency-issued regulations impose additional constraints to prescription and dispensing. Since the law makes no provision for thalidomide analogs such as lenalidomide, Brazil has clearly adopted a regulatory double standard for thalidomide and thalidomide-like teratogens marketed by pharmaceutical companies. A thorough search was conducted in biomedical electronic databases (Medline/Pubmed, BVS Brazil/Bireme, http:// www.brasil.bvs.br), to identify comparative effectiveness and safety studies of thalidomide versus lenalidomide for treatment of multiple myeloma and or myelodysplastic syndrome (MDS). A similar search was undertaken to find comparative cost-effectiveness studies of thalidomide-versus lenalidomide-based therapies for MM and MDS. Searches in Medline and BVS Brazil/Bireme databases were conducted using a variety of searching strings (e.g., "lenalidomide AND thalidomide AND comparative effectiveness"; "lenalidomide AND thalidomide AND multiple myeloma AND effectiveness"; "thalidomide AND myeloma AND

effectiveness AND safety"; and others), and covered a time window between database inception and October $31^{\text {st }}, 2017$. Reference lists of articles and documents were examined to find any additional relevant study. Furthermore, the author went over the Virtual Library on Health of the Brazilian Ministry of Health website (BVS MS, www.bvsms.saude.gov.br/index.php), and the Brazilian Sanitary Surveillance Agency (Anvisa) compilation of legislation on health products to identify all regulations and laws potentially applicable to this regulatory drug topic.

\section{Results and Discussion}

\section{Brief regulatory history of thalidomide and lenalidomide in the US and Brazil}

Owing to its teratogenicity, and because prevalence of Hansen disease is almost negligible in the country, thalidomide was not approved for sale in the US until 1998 when, in an attempt to put an end to smuggling and uncontrolled use of the drug for a variety of medical conditions, the US FDA approved it. Curiously, the first authorized therapeutic indication for thalidomide (Thalomid ${ }^{\circledast}$ made by Celgene ${ }^{\oplus} \mathrm{Co}$ ) was erythema nodosum leprosum (ENL), or type-2 reaction, a medical condition extremely rare, or even nonexistent in the US. Only a few years later, in May 2006, FDA granted accelerated approval for thalidomide (in combination with dexamethasone) for the treatment of newly diagnosed multiple myeloma (MM) patients. The German company Chemie Grünenthal GmbH had launched thalidomide in 1957, and thus it has no longer patent protection. Nonetheless, a patent was granted to Celgene ${ }^{\varpi}$ Co for its System for Thalidomide Education and Prescribing Safety (STEPS ${ }^{\circledR}$ Program, a restricted distribution system intended to prevent thalidomide use by pregnant women) what means in practice that Thalomid ${ }^{\varpi}$ has a marketing exclusivity in the US3

Lenalidomide (Revlimid ${ }^{\Phi}$ ) was the first thalidomide-like drug obtaining a marketing authorization (Figure 1). It was developed by Celgene Co and approved by the FDA for treatment of myelodysplastic syndrome (MDS) and multiple myeloma (MM) in 2005 (December) and 2008, respectively. The European Medicines Agency (EMA), on the other hand, granted a marketing authorization for lenalidomide use in MM (in combination with dexamethasone for patients who had received at least one prior therapy), in 
2007, and for use in MDS, in 2013. In the EU and US, the approved indications for lenalidomide were further expanded to include previously untreated MM patients who were not eligible for transplants, monotherapy for the maintenance treatment of patients with newly diagnosed MM (after autologous stem cell transplantation), and for therapy of mantle cell lymphoma in patients whose disease had relapsed, or progressed after two prior therapies. Lenalidomide costs nearly US $\$ 163,381$ per year for the average patient ${ }^{4}$ and thus lenalidomide-based therapies are much costlier than thalidomide-based treatments for MM. Both FDA and EMA awarded an orphan drug status/designation to lenalidomide because of the rarity of multiple myeloma. Data from the National Cancer Institute (NCI) informs that, in the US, the incidence (new cases) of MM was 6.6 per 100,000 men and women per year, and that, in 2014 , there were estimated 118,539 people living with $\mathrm{MM}$ in the country ${ }^{5}$. Notwithstanding the "orphan drug" status, lenalidomide (Revlim$\mathrm{id}^{\circledast}$ ) proved to be a highly profitable product. It was Celgene ${ }^{\varpi}$ Co’s blockbuster drug with sales in the first 2017 quarter of US\$ 1,884 million against US\$26 million for Thalomid ${ }^{\circledast}$ in the same period $^{6}$.

In 2008, Zodiac ${ }^{\circledR}$ Co (a company licensed by Celgene $^{\varpi}$ Co to sell Revlimid ${ }^{\circledast}$ in Brazil) filed an application for lenalidomide use in MM and MDS that the Brazilian agency ANVISA rejected in 2010. The rejection was based on a report by the Advisory Committee on Medicines (CATEME) whose members pointed out that the applicant provided no evidence that lenalidomide was more effective and or safer than thalidomide for both therapeutic indications. On the understanding that, similarly to thalidomide, lenalidomide also proved to be a strong teratogen in non-human primates, and that it is much more expensive than its prototype drug, CATEME recommended that the applicant should provide sound evidence that lenalidomide is clinically superior to thalidomide (to be demonstrated by comparative effectiveness research data) before a marketing authorization is granted. The negative decision was followed by a powerful lobbying at the forefront of which were patient organizations, medical specialty societies, politicians and Congress members. In 2012, ANVISA's board of directors denied a request for reconsideration filed by Zodiac ${ }^{\circledast}$ Co thereby confirming the application rejection. In April 2017, ANVISA ignored all the reasons for the first application rejection and, in an unexplained retreat, approved lenalid- omide registration in the country. Nonetheless, the publication of the positive decision on registration, that ultimately enacts the authorization for sales, still depends on a special regulation on the control of its use and dispensing to be issued by the agency ${ }^{7}$.

\section{Comparative effectiveness of lenalidomide and thalidomide in the treatment of multiple myeloma}

\section{Thalidomide}

The notion that antiangiogenic compounds could be useful to treat some types of cancer stands on the observation that solid tumors required neovascularization (angiogenesis) for growth and survival ${ }^{7}$. In 1994, D'Amato et al. reported that thalidomide inhibited angiogenesis in the rabbit cornea assay ${ }^{8}$. The next logical step was to test thalidomide in patients with cancer. An open-label (uncontrolled) trial with relapsed and/or refractory MM patients showed that, as anticipated by Folkman's hypothesis, thalidomide was active against advanced tumors, caused a decline in the serum and urine levels of paraprotein (the primary efficacy outcome), a disease remission and apparently an improvement of survival ${ }^{9}$. Since then, evidence from a set of phase II studies confirmed that thalidomide (with dexamethasone and or chemotherapy) significantly improved overall response rates to combined therapies for relapsed and newly diagnosed patients ${ }^{10,11}$. A further phase III randomized clinical trial also showed that, compared to "dexamethasone alone", "thalidomide plus dexamethasone" gave rise to superior responses rates in newly diagnosed MM patients ${ }^{12}$.

\section{Lenalidomide}

A phase III placebo-controlled trial revealed that, in patients with relapsed or refractory MM, lenalidomide combined with dexamethasone significantly prolonged "time to progression" (11.3 months versus 4.3 months), and improved overall survival $^{13}$. In newly diagnosed MM patients ineligible for bone-marrow transplantation, maintenance with lenalidomide after an induction treatment regimen (melphalan + prednisone + lenalidomide) was shown to prolong "progression-free survival" compared with the induction therapy followed by placebo ${ }^{14}$. A meta-analysis of seven RCTs evaluating initial or maintenance therapeutic outcomes, such as response rates, "progression-free survival" (PFS), "overall survival" and adverse effects, concluded 
that complete and very good partial response risk ratios, and PFS hazard ratios favored lenalidomide over placebo ${ }^{15}$. The occurrence of adverse events (neutropenia, deep vein thrombosis, infection and hematologic cancer), however, favored placebo over lenalidomide ${ }^{16}$.

In summary, phase II and III clinical studies showed that both thalidomide- and lenalidomide-based combination therapies were effective and safe, that is, they substantially improved clinical outcomes such as "progression free survival" and "overall survival" in patients with multiple myeloma (MM). Therapeutic regimens based on thalidomide, lenalidomide and, more recently, on the proteasome inhibitor drug bortezomid (it diminishes the activity of cell proteasomes that break down proteins including those that kill malignant cells), revolutionized the therapy of MM, formerly a hematologic cancer of poor prognosis. $\mathrm{MM}$ is a plasma cell proliferative disorder that leads to an accumulation of neoplastic cells (a solid tumor) in the bone marrow. The beneficial effects of thalidomide- and lenalidomidecombined therapies in MM patients apparently arise from a dual mechanism of action, while the antiangiogenic activity rapidly reduces MM burden, their long-term immunomodulatory actions seems to maintain tumor suppression ${ }^{17}$. Effective therapeutic regimens for MM usually also include an antimitotic drug (e.g., melphalan, a potent nitrogen mustard related alkylating agent) and a glucocorticoid (e.g., dexamethasone or prednisone).

\section{Comparative effectiveness of thalidomide-} versus lenalidomide-based therapies

Although presenting similar biological activities, lenalidomide is more potent than thalidomide, i.e., it achieves responses at lower doses. Higher potency, however, does not imply greater clinical efficacy and two drugs may have different potencies and the same efficacy.

To the best of our knowledge, only two randomized (phase-III) trials have compared the effectiveness of thalidomide-based versus lenalidomide-based therapeutic regimens so far (Table 1). Stewart et al. ${ }^{18}$ conducted a phase III RTC to compare (with a non-inferiority design) a "melphalan-prednisone-thalidomide" induction and maintenance with thalidomide (MPT-T) with "melphalan-prednisone-lenalidomide (Revlim$\left.\mathrm{id}^{\circledast}\right)$ " and maintenance with lenalidomide (MPR-R) in elderly patients with untreated MM. Results showed that there was no difference between MPT-T and MPR-R in response rates, pro- gression free survival (PFS) and overall survival. MPR-R, however, presented a lower occurrence of peripheral neuropathy side effects (Table 1). A similarly designed multicenter open-label RCT by Zweegman et al. ${ }^{19}$ compared MPT-T and MPR-R regimens in newly diagnosed MM patients who were ineligible for stem cell transplantation. Again, this second study showed no superiority of MPR-R over MPT-T regarding clinical efficacy (PFS). The trial found, however, an increased occurrence of neuropathy in MPT-T, and of hematologic toxicity requiring growth factor support in MPR-R (Table 1).

In addition to the foregoing RCTs, three non-interventional studies also addressed comparative effectiveness of thalidomide- versus lenalidomide-based combination regimens in the therapy of MM (Table 1). A retrospective case-control study (matched-pair analysis adjusted for age, sex, transplantation status, and dexamethasone dose) by Gay et al. ${ }^{20}$ compared the efficacy and safety of "thalidomide plus dexamethasone" versus "lenalidomide plus dexamethasone" as the initial therapy for newly diagnosed MM. The authors concluded that lenalidomide-dexamethasone was well tolerated and more effective than thalidomide-dexamethasone. This retrospective study, however, has a number of important methodological limitations, including the fact that patients treated with thalidomide-dexamethasone received different doses of thalidomide. It is of note that nearly all authors informed having received honoraria from Celgene $^{\circledast}$ Co in their conflict-of-interest disclosure statement. An observational retrospective study conducted in India (analysis of medical record files) compared the efficacy and occurrence of adverse events in 17 patients (newly diagnosed MM) that had received thalidomide-dexamethasone with 19 patients treated with lenalidomide-dexamethasone ${ }^{18}$. The authors found no difference between thalidomide- and lenalidomide-based therapies with respect to efficacy and safety ${ }^{21}$. A recent population-based cohort study by Luo et al. ${ }^{22}$ compared survival and rates of peripheral neuropathy in MM patients $(n=1264)$ receiving either thalidomide or lenalidomide in routine care in the US. The study found no difference in rates of death (hazard ratio, 95\% CI, $1.00,0.71-1.41)$ and a lower risk of peripheral neuropathy associated with lenalidomide $(0.71$, 0.56-0.92).

Overall, available comparative effectiveness studies showed no difference in efficacy between lenalidomide- and thalidomide-based therapies 


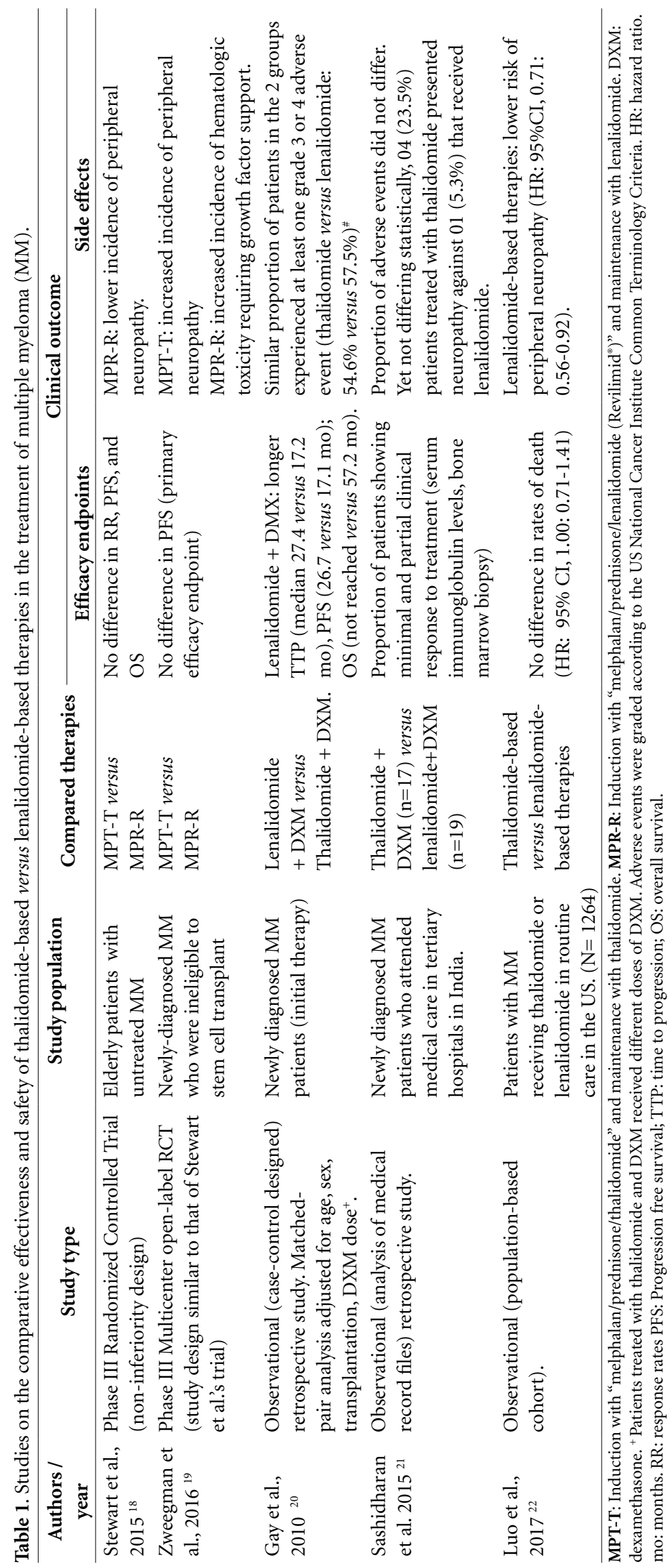


Lenalidomide approval for marketing in Brazil is an unquestionable triumph of a lobbying involving Congress members, patient organizations (most of which supported by the pharmaceutical company) and medical specialty associations. As always, lobbying campaign blurred the scientific evidence behind the arguments for and against an approval for marketing decision.

Lenalidomide, thalidomide and proteasome inhibitors (bortezomid) are effective drugs that have revolutionized the treatment of MM. Comparative effectiveness research failed to demonstrate a greater efficacy of lenalidomide over thalidomide or bortezomid in patients with $\mathrm{MM}^{18-21,23}$. All these drugs can cause potentially severe adverse effects but their toxicity profiles are somewhat different from each other. For instance, lenalidomide, compared to thalidomide, apparently causes less peripheral neuropathy and more severe hematologic toxicity.

If comparative effectiveness research do not reveal a clinical superiority of lenalidomide over the other drugs, cost-effectiveness seems to be different. Thalidomide-based treatments are cost-effective compared with those based on lenalidomide. This was shown by a study comparing the cost-effectiveness of initial treatment of MM in the US with "bortezomid (Velcade ${ }^{\circledR}$ + melphalan + prednisone" (VMP), versus "thalidomide + melphalan + prednisone" (MPT), versus "lenalidomide (Revlimid") + melphalan + prednisone plus lenalidomide maintenance" (MPR-R), and found that VMP cost $\$ 119,102$, MPT $\$ 142,452$ and MPR-R $\$ 248,358^{24}$. Thalidomide-based therapies, however, are certainly much cheaper in Brazil where a state-owned pharmaceutical industry (FUNED-MG) produces - at very low manufacturing costs - the thalidomide used in the country. It was estimated, for instance, that US brand-name thalidomide (Thalomid $^{\varpi}$ ) costs approximately 122 -fold the thalidomide made by Brazilian FUNED². Therefore,

the eventual substitution of thalidomide-based therapies by those based on lenalidomide is likely to raise substantially healthcare costs in the country without a significant (if any) improvement of treatment effectiveness.

Another major problem with lenalidomide approval in Brazil is the establishment of a regulatory double standard for analogous drugs having in common a high teratogenic risk (Table 2). Owing to risk of harm to the unborn child, thalidomide is regulated by a specific Federal law (Law No.10.651/2003) that prohibits its sale and or dispensing in commercial pharmacies. It also states that thalidomide shall be distributed exclusively to public health units and hospitals. There are a number of additional rules issued by ANVISA that impose strict conditions for prescribing and dispensing thalidomide to approved (and off label) therapeutic indications. The law 10.651/2003, however, makes no provision for lenalidomide and other teratogenic analogues of thalidomide. Unless the Brazilian Congress amends law 10.651/2003, lenalidomide sale, prescribing and dispensing will be regulated exclusively by ANVISA rules, i.e., by agency resolutions that do not have the force of law. Recently, ANVISA conducted a public consultation (CP No. 393/2017) on a Regulatory Act on the control of lenalidomide. A key difference regarding the current thalidomide control regulation in the country is that, in the case of lenalidomide, it is up to the drug manufacturing company the implementation of a detailed plan on the sales, distribution and dispensing that must comply with a Pregnancy Prevention Plan approved by the agency (Table 2).

Finally, there is no reason for a regulatory double standard for lenalidomide and thalidomide and, therefore, law 10.651/2003 should be amended to include lenalidomide and any other thalidomide analogue. The rules for prescription and dispensing of lenalidomide should be the same prevailing for thalidomide and thus, promotion of lenalidomide prescription and advertisement by the pharmaceutical company should be forbidden. The use of lenalidomide should be controlled by health authorities and restricted to those patients who cannot otherwise be treated with more cost-effective alternatives (e.g., because of peripheral neuropathy side effects). 
Table 2. Brazilian asymmetric regulatory standards for thalidomide and its teratogenic analogue lenalidomide.

\begin{tabular}{|c|c|c|}
\hline & Thalidomide & Lenalidomide \\
\hline Brand name & Generic name & Revilimid $^{\oplus}$ \\
\hline Manufacturer & $\begin{array}{l}\text { State owned (public) industry } \\
\text { (FUNED-MG) }\end{array}$ & $\begin{array}{l}\text { Pharmaceutical company (Celgene } \\
\text { Co) }\end{array}$ \\
\hline $\begin{array}{l}\text { Potential to cause birth defects } \\
\text { (teratogenicity) }\end{array}$ & $\begin{array}{l}\text { Proven to humans and non-human } \\
\text { primates }\end{array}$ & $\begin{array}{l}\text { Proven to non-human primates } \\
\text { (likely human teratogen) }\end{array}$ \\
\hline Regulation & $\begin{array}{l}\text { Federal Law }(10.651 / 2003) \text { and } \\
\text { additional rules issued by ANVISA }\end{array}$ & $\begin{array}{l}\text { Regulation to be issued by ANVISA } \\
\text { (Public Consultation No. 393/2017) }\end{array}$ \\
\hline Sales & Prohibited & No restriction. \\
\hline Costs & Low cost medicine & (very) High cost medicine \\
\hline $\begin{array}{l}\text { Promotion of Prescription \& } \\
\text { Advertisement }\end{array}$ & Prohibited (nonexistent) & $\begin{array}{l}\text { Allowed if directed to prescribers } \\
\text { (as any other prescription drug) }^{+}\end{array}$ \\
\hline $\begin{array}{l}\text { Use for off-label therapeutic } \\
\text { indications }\end{array}$ & Strictly controlled by ANVISA & Uncontrolled by ANVISA \\
\hline Drug distribution and dispensing & $\begin{array}{l}\text { Exclusively to public health units } \\
\text { and hospitals (controlled by health } \\
\text { authorities) }\end{array}$ & $\begin{array}{l}\text { Distribution and dispensing } \\
\text { controlled by the company }\end{array}$ \\
\hline $\begin{array}{l}\text { Authorized prescribers / } \\
\text { pharmacists }\end{array}$ & Registered by local health authority & $\begin{array}{l}\text { Qualified and registered by the } \\
\text { company. }\end{array}$ \\
\hline
\end{tabular}




\section{References}

1. DiMasi JA, Faden LB. Competitiveness in follow-on drug R\&D: a race or imitation? Nat Rev Drug Discov 2011; 10(1):23-27.

2. Paumgartten FJ. Novel thalidomide analogues, "me too" drugs and the Brazilian law. Visa em Debate 2013; 1:2-10.

3. Sarpatwari A, Avorn J, Kesselheim AS. Using a drug-safety tool to prevent competition. $N$ Engl J Med 2014; 370(16):1476-1478.

4. Badros AZ. Lenalidomide in myeloma--a high-maintenance friend. N Engl J Med 2012; 366(19):18361838.

5. National Cancer Institute (NCI). Surveillance, Epidemiology and End Results program [Internet]. Cancer Stat facts: Myeloma [cited 2017 Nov 10]. Available at: https://seer.cancer.gov/statfacts/html/mulmy.html

6. Celgene. Celgene Reports First Quarter 2017 Operating and Financial results. [cited 2017 Nov 12]. Available at: http://ir.celgene.com/releasedetail.cfm?releaseid= 1023223

7. Brasil. Ministério da Saúde (MS). Agência Nacional de Vigilância Sanitária - Anvisa. CP 393, 12 September 2017. Proposta sobre controle da substância lenalidomida e do medicamento que a contenha. [cited 2017 Oct 31]. Available at: http://portal.anvisa.gov.br/rss/ asset_publisher/Zk4q6UQCj9Pn/content/id/3605796

8. D'Amato RJ, Loughnan MS, Flynn E, Folkman J. Thalidomide is an inhibitor of angiogenesis. Proc Natl Acad Sci USA 1994; 91(9):4082-4085.

9. Folkman J. Tumor angiogenesis: therapeutic implications. N Engl J Med 1971; 285(21):1182-1186.

10. von Lilienfeld-Toal M, Hahn-Ast C, Furkert K, Hoffmann F, Naumann R, Bargou R, Cook G, Glasmacher A. A systematic review of phase II trials of thalidomide/dexamethasone combination therapy in patients with relapsed or refractory multiple myeloma. Eur J Haematol 2008; 81(4):247-252.

11. Singhal S, Mehta J, Desikan R, Ayers D, Roberson P, Eddlemon P, Munshi N, Anaissie E, Wilson C, Dhodapkar M, Zeddis J, Barlogie B. Antitumor activity of thalidomide in refractory multiple myeloma. $N$ Engl J Med 1999; 341(21):1565-1571.

12. Moehler TM, Hillengass J, Glasmacher A, Goldschmidt $\mathrm{H}$. Thalidomide in multiple myeloma. Curr Pharm Biotechnol 2006; 7(6):431-440.

13. SV, Blood E, Vesole D, Fonseca R, Greipp PR; Eastern Cooperative Oncology Group. Phase III clinical trial of thalidomide plus dexamethasone compared with dexamethasone alone in newly diagnosed multiple myeloma: a clinical trial coordinated by the Eastern Cooperative Oncology Group. J Clin Oncol 2006; 24(3):431-436.

14. Dimopoulos M, Spencer A, Attal M, Prince HM, Harousseau JL, Dmoszynska A, San Miguel J, Hellmann A, Facon T, Foà R, Corso A, Masliak Z, Olesnyckyj M, Yu Z, Patin J, Zeldis JB, Knight RD; Multiple Myeloma (010) Study Investigators. Lenalidomide plus dexamethasone for relapsed or refractory multiple myeloma. N Engl J Med 2007; 357(21):2123-2132.
15. Palumbo A, Hajek R, Delforge M, Kropff M, Petrucci MT, Catalano J, Gisslinger H, Wiktor-Jędrzejczak W, Zodelava M, Weisel K, Cascavilla N, Iosava G, Cavo M, Kloczko J, Bladé J, Beksac M, Spicka I, Plesner T, Radke J, Langer C, Ben Yehuda D, Corso A, Herbein L, Yu Z, Mei J, Jacques C, Dimopoulos MA; MM-015 Investigators. Continuous lenalidomide treatment for newly diagnosed multiple myeloma. $N$ Engl J Med 2012; 366(19):1759-1769.

16. Yang B, Yu RL, Chi XH, Lu XC. Lenalidomide treatment for multiple myeloma: systematic review and meta-analysis of randomized controlled trials. PLoS One 2013; 8(5):e64354.

17. Morgan G. Future drug developments in multiple myeloma: an overview of novel lenalidomide-based combination therapies. Blood Rev 2010; 24(Supl. 1):S27-S32.

18. Stewart AK, Jacobus S, Fonseca R, Weiss M, Callander NS, Chanan-Khan AA, Rajkumar SV. Melphalan, prednisone, and thalidomide vs melphalan, prednisone, and lenalidomide (ECOG E1A06) in untreated multiple myeloma. Blood 2015; 126(11):1294-1301.

19. Zweegman S, van der Holt B, Mellqvist UH, Salomo M, Bos GM, Levin MD, Visser-Wisselaar H, Hansson M, van der Velden AW, Deenik W, Gruber A, Coenen JL, Plesner T, Klein SK, Tanis BC, Szatkowski DL, Brouwer RE, Westerman M, Leys MR, Sinnige HA, Haukås E, van der Hem KG, Durian MF, Mattijssen EV, van de Donk NW, Stevens-Kroef MJ, Sonneveld P, Waage A. Melphalan, prednisone, and lenalidomide versus melphalan, prednisone, and thalidomide in untreated multiple myeloma. Blood 2016; 127(9):1109-1116.

20. Gay F, Hayman SR, Lacy MQ, Buadi F, Gertz MA, Kumar S, Dispenzieri A, Mikhael JR, Bergsagel PL, Dingli D, Reeder CB, Lust JA, Russell SJ, Roy V, Zeldenrust SR, Witzig TE, Fonseca R, Kyle RA, Greipp PR, Stewart AK, Rajkumar SV. Lenalidomide plus dexamethasone versus thalidomide plus dexamethasone in newly diagnosed multiple myeloma: a comparative analysis of 411 patients. Blood 2010; 115(7):1343-1350.

21. Sashidharan N, Shenoy S, Kishore MK, Thanusubramanian H. Comparison of Two Therapeutic Regimes, Lenalidomide with Dexamethasone and Thalidomide with Dexamethasone, in the Treatment of Multiple Myeloma at a Tertiary Care Hospital in India. J Clin Diagn Res 2015; 9(5):XC01-XC04.

22. Luo J, Gagne JJ, Landon J, Avorn J, Kesselheim AS. Comparative effectiveness and safety of thalidomide and lenalidomide in patients with multiple myeloma in the United States of America: A population-based cohort study. Eur J Cancer 2017; 70:22-33.

23. Wang A, Duan Q, Liu X, Ding K, Han Y, Zhu W, Sun Z. (Bortezomib plus lenalidomide / thalidomide)- vs. (bortezomib or lenalidomide / thalidomide)-containing regimens as induction therapy in newly diagnosed multiple myeloma: a meta-analysis of randomized controlled trials. Ann Hematol 2012; 91(11):17791784 . 
24. Garrison Junior LP, Wang ST, Huang H, Ba-Mancini A, Shi H, Chen K, Korves C, Dhawan R, Cakana A, van de Velde H, Corzo D, Duh MS. The cost-effectiveness of initial treatment of multiple myeloma in the U.S. with bortezomib plus melphalan and prednisone versus thalidomide plus melphalan and prednisone or lenalidomide plus melphalan and prednisone with continuous lenalidomide maintenance treatment. Oncologist 2013; 18(1):27-36.

Artigo apresentado em 05/12/2017

Aprovado em 12/03/2018

Versão final apresentada em 15/03/2018 